\section{The Role of Horticulture in Training Correctional Youth}

\author{
Joel Flagler'
}

Additional index words. corrections, horticulture-youth, horticultural therapy

Summary. Since 1992, Rutgers University-Cook College has been working with the New Jersey Dept. of Corrections and Division of Juvenile Services to develop and deliver training programs. One goal of this specialized training has been to make New Jersey's adjudicated youth more employable. Another goal has been to impart personal development skills that can lead to improved self-esteem and outlook.

$\mathrm{A}$ $s$ it enters into its fourth year, the Rutgers Univ. horti cultural training program has evolved in response to several factors, including changes in finding patterns and sponsorship. Changes in curriculum also have resulted, as participants indicate strong preferences for certain subject matter over others. Consequently, the correctional youth training programs on tap for 1995 are somewhat different from those implemented 3 years ago. While personal development and new vocational skills attainment are still primary goals, there is new emphasis on sparking interest in hobbies, community beautification, and respect for the environment and other living things. The new spin-off programs will include Butterflies and Entomology, Job Readiness, and Bonsai Culture.

New directions in education and rehabilitation are not particular to the correctional system in New Jersey. Across the United States there are

\footnotetext{
${ }^{1}$ Associate professor, Rutgers University-Cook College, and agricultural-resource management extension agent for Bergen County, Current address 327 Ridgeewood Avenue, Paramus, N.J.

The cost of publishing this paper was defrayed in part by the payment of page charges. Under postal regulations, this paper therefore must be hereby marked advertise ment solely to indicate this fact.
}

programs that are progressive departures from failed traditional approaches. Hands-on, career-oriented training has been very effective in motivating incarcerated individuals (Rice, 1994; C. Sneed, unpublished data). In many successful applications, horticulture has been used as an important tool in the education and rehabilitation process. It is postulated that the benign nature of plant-related activities helps create a nonthreatening atmosphere in which participants can take their first steps toward success. The heightened sense of self-confidence may enable an individual to pursue a career path and reintegration into community life.

Since 1978, the National Gardening Association has been involved in designing gardens and gathering information on institutional horticultural programs. What they have found is that, where there is a highly organized cooperative effort, gardens in correctional facilities can produce enough food to result in significant cost savings for meals (Flinn, 1985). There is, however, much more than just the cost benefit.

For the incarcerated individual, the presence of plants and nearby na-

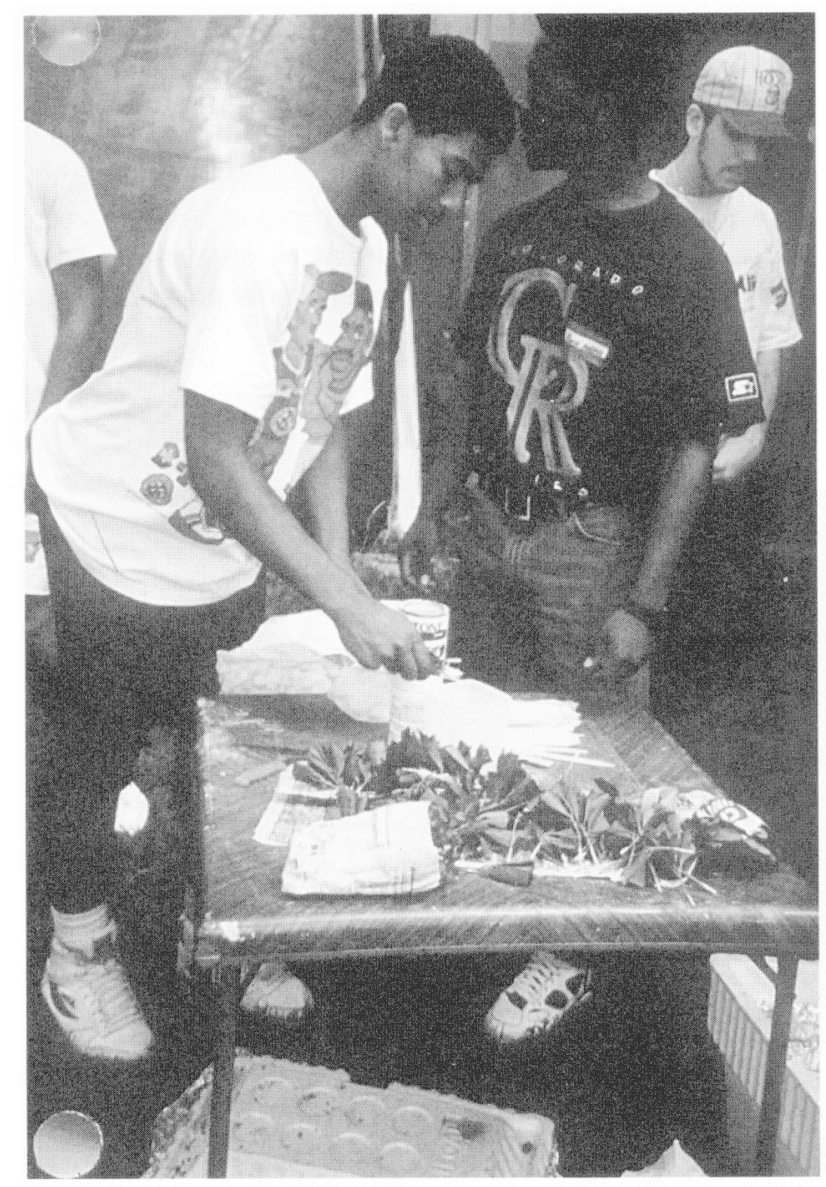

ture can provide relief from the stress of overcrowded indoor confinement (Kaplan, 1992; Moore, 1981). Handson horticulture programs go a step further by offering opportunities for meaningful outdoor work. Such programs also can provide important job training and instill regular work habits and behaviors. Further, participants can learn to tolerate frustration and manage impulsive and negative behavioral responses. All of this can work toward improving self-esteem. As selfevaluation surveys indicate (Flagler, 1994), incarcerated youths often feel that little they do ever-turns out right. Yet, in a horticultural setting, participants can be taught to plan,work appropriately, and harvest the fruits of their labor. For many, this is the first rewarding experience they have ever had.

\section{Benefits to the individual}

The benefits of horticultural programs in correctional settings maybe impressive. They can include the following.

Provide activity. Corrections officials and incarcerated individuals agree on the importance of meaningful work activity. Individuals are less apt to cause trouble while engaged in gardening as opposed to sitting idly, which causes mental, physical, and emotional deterioration (Flinn, 1985). Food and ornamental crop production is fruitful. It is not makework, and participants recognize that fact. Horticulture affords an opportunity to see the value of working today for benefits tomorrow.

Gardens produce quality food. There is no question that garden produce is popular.

Fig. 1. In many successful applications, horticulture has been used as an important tool in the education and rehabilitation process. 
Fresh fruit and vegetables disappear fast when offered in a correctional facility's food line. Many prison officials have observed a close relationship between the quality of foods offered and the behavior of inmates. A frequent grievance in correctional facilities is "lousy food!" Fresh produce grown by the garden program is a welcome relief from typical overcooked institutional fare. This can work toward improving the quality of life in the institution (W. Young, personal communication).

Horticulture offers good learning experience. Important learning opportunities are created when a program includes course work and handson activity in a variety of settings. A mixture of garden, greenhouse, and classroom training can contribute valuable skills that increase an individual's chance of success in the job market. Work ethic, responsibility, basic social skills, problem-solving, and decisionmaking are important in training for future employment.

Success in horticulture. Behind most incarcerated individuals is a long list of failures. Even in young offenders there usually has been failure in school, family life, and the job market. As a member of a gardening crew or other

$\begin{array}{ll}\text { Fig. 2. As a } & \text { horticulture work } \\ \text { member of a } & \text { team, an indi - } \\ \text { gardening crew or } & \text { vidual may have } \\ \text { other borticulture } & \text { the first opportu- } \\ \text { work team, an } & \text { nity to succeed } \\ \text { individual may } & \text { and, in doing so, } \\ \text { bave bis or ber first } & \text { build self-confi- } \\ \text { opportunity to } & \text { dence. Success } \\ \text { succed. } & \end{array}$

with plants can lead to success in other aspects of an individual's life, personal and professional. (Lewis, 1972).

It generally is agreed that recognition is an important aspect of perceived success. Many horticultural programs in correctional facilities reward the participants for a job well done. This contributes to heightened self-esteem, which results from a successful garden or the completion of a greenhouse project. Rutgers Univ., like other sponsoring institutions and agencies nationwide, gives out certificates to all correctional youths who participate in the horticulture training program. For most of the individuals, this is their first certificate of achievement.

\section{Program objectives}

Objectives vary from program to program, depending on the long-range goals set forth for a particular incarcerated population. In the Rutgers program, a set of objectives was established to help develop the course content. These objectives included the following.

1 To develop an understanding that knowledge of horticultural practices can be used as a life skill.

1 To impart an awareness of occupational safety and an understanding of the tools and small machinery used in gardening and landscaping.

1 To develop tolerance and patience and the ability to cooperate with fellow workers and appreciate what it means to be part of a work team.

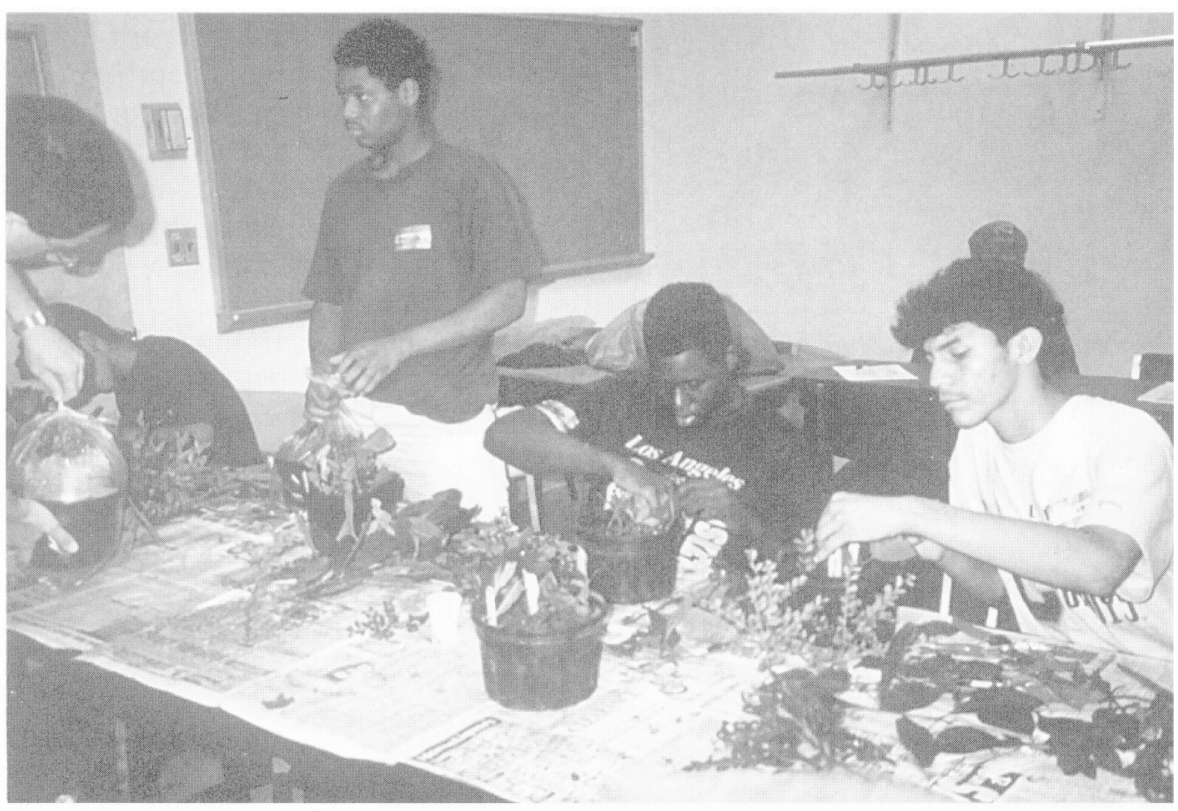

- To learn how to take initiative and to accept responsibility for one's actions.

- To take pride in horticultural accomplishments and appreciate plants as living organisms that respond to human intervention.

- To listen and follow instructions and to apply them to the task at hand and exercise decisionmaking and problem-solving capabilities.

\section{Program outline}

A stated set of objectives makes it possible to develop an outline for the horticultural training program. These objectives provide a workable frame around which the lessons and training modules can be structured.

The Rutgers program has divided the training into several broad categories. While hands-on activities are clearly preferred, the participants must learn to tolerate and appreciate the importance of a more formalized classroom lesson. The broad categories of training include the following.

- Introduction to Horticulture. This focuses on the history and importance of horticulture and its relationships to people. Upto-date information about career opportunities within different specialty areas is stressed.

- Fundamentals of Plant Care. It is essential that trainees understand the basics of plant structure and function. The effects of light, air, water, and nutrition on plant growth and development are discussed. Audio-visual aids including slides and video, help make the plant science lessons more palatable.

- Common Landscape Plants. The trainees become familiarized with a dozen commonly used ornamental trees and shrubs. Each trainee prepares a herbarium, collecting leaves and assembling information used in identifying the different species. The focus is to impart an understanding of the cultural requirements of various plants, while emphasizing their proper use in a landscape setting.

- Nursery Practices. The basic practices of a plant nursery are presented, enhanced by field trips to actual commercial operations. Also identified are common nursery and greenhouse tools, equipment and supplies. 
- Grounds Maintenance. This section looks at the basic practices involved in turf and grounds maintenance. Students learn about the commonly used equipment and supplies and their correct application to horticultural tasks.

- Vegetable and Flower Gardening. Participants start annual plants from seed and, for 10 weeks, nurture and transplant the seedlings in a greenhouse. Ultimately, they transplant their seedlings into beds at the Rutgers Display Garden, incorporating their own designs and garden plans.

\section{Program implementation}

Training modules are structured carefully, as many participants ranging in age from 15 to 18 have third- and fourth-grade reading levels. Attention spans are often very limited, and traditional teaching approaches have frequently failed these youths. Many class sessions are held on the Rutgers-Cook College campus, using classroom, greenhouse, and field-site settings. To provide continuity, classes are also delivered at the correctional facility where ever appropriate.

Typically, a short (50-min) lecture using audio-visual aids is followed by a 1.5-h hands-on activity. After a 1$h$ lunch break in the campus student center, there is a structured outdoor activity or field trip relating to the morning lesson theme. Outdoor activities include pruning trees and transplanting nursery stock. Field trips give students a chance to visit commercial horticultural operations and experience actual employment settings. These include golf courses, sod fares, production greenhouses, and nurseries.

Funding for the last 3 years has been secured from three state sources, including the New Jersey Dept. of Corrections, Division of Human Services, and Dept. of Environmental Protection. There is no way to predict future patterns of funding and program sponsorship. However, the Rutgers horticulture training program for correctional youth has demonstrated its effectiveness and is generally perceived to be an innovative and important educational tool.

\section{Evaluation results}

The evaluation method for the Rutgers Careers in the Green Industry program includes three levels of feed- back: by students, correctional staff, and Rutgers-Cook College faculty and instructors. Each month, program participants complete surveys to give them a chance to express perceptions and attitudes toward plants, hands-on activities, and classroom lectures.

From the 54 surveys returned in 1994, several important findings became clear. While the sample size is relatively small, many of the evaluation responses were similar to responses obtained in 1993 and 1992, which had sample sizes of 140 and ,60, respectively.

For $85 \%$ of those responding, the Rutgers training program was the first opportunity to be inside a college classroom. The same $85 \%$ indicated that this experience had sparked interest in going to college. This finding is supported by the narrative statements the students offered: "It makes me feel like a college student...I enjoy it"; "It makes me feel important"; "It's very bright and clean"; "It makes me feel like somebody cares"; and many variations of this theme.

Over $80 \%$ of the participants responded positively when asked if the Rutgers training program had given them some ideas about possible careers. This carries more importance than might be assigned to it immediately. In entry interviews, only about $15 \%$ of the students expressed any interest in green-industry careers.

Another interesting set of survey responses came when participants were asked if, as a result of the training program, they think they can improve the quality of their lives. Eight yseven percent responded yes and checked off one or more of the following reasons:

- I have more job skills $(80 \%)$.

- I have experience that may help me get a job $(75 \%)$.

- I have made contacts with people that could help me someday $(71 \%)$.

- I have ideas about future schooling or training $(71 \%)$.

The $13 \%$ of the respondents who did not agree that they could improve the quality of their lives as a result of the program gave the following reasons: they either do not like plants or do not believe that horticulture training can help them prepare for better futures.

Eighty-five percent of those responding felt that the post-training classes on preparing a resume and job application were ofgreat benefit to them.
Ninety percent agreed that the session on preparing for a job interview, including mock interviews with Rutgers faculty, made them feel more prepared and confident about getting a job.

Ending with a positive note, $82 \%$ of the participating students indicated that, as a result of the Rutgers-Cook College Careers in the Green Industry program, they believed they could teach something to someone else.

Aside from the statistical indicators, the narrative statements contained in the surveys provided encouragement and justification for program sustainment and expansion, provided a call for developing new programs and further research into the role of horticulture as a tool for rehabilitating correctional youths. Actual responses include the following.

- "If we ever run out of food I can plant some."

- "Plants make life possible and make people happy."

- "Before, I used to kill plants and step on them" and "I am now beginning to understand the relationship between people and plants."

It has been observed that the process of horticulture can have measurable effects on the human participants. Anyone can be successful with plants, regardless of mental, physical, emotional, and social disabilities. The potentials for using horticulture as a tool to train and rehabilitate correctional youth are only beginning to be explored. As a result of repeated success in a variety of settings, there is clearly justification for further research into the role of horticulture in human wellbeing and social development.

\section{Literature Cited}

Flagler, J. 1994. Corrections and the green industry.J. Home and Consumer Hort. 1(4):283-290.

Flinn, N. 1985. The prison garden book. Natl. Gardening Assn., Vermont.

Kaplan, R. 1992. The psychological benefits of nearby nature, p. 125-133. In: D. Relf(ed. ). The role of horticulture in human well-being and social development. Timber Press, Portland, Ore.

Lewis, C.A. 1972. Public housing gardens-Landscapes for the soul, p. 277-282. In: Landscapes for living. U.S. Dept. of Agr. Ybk Agr.

Moore, E.O. 1981. A prison environment's effect $\mathrm{cm}$ healthcare service demands. J. Environ. Systems 11:17-34.

Rice, J.S. 1994. Evaluating horticultural therapy: The ecological context of urban jail inmates, $\mathrm{p}$. 203-224. In: J. Flagler (cd.). People-plant relationships: Setting research priorities. Haworth Press. 